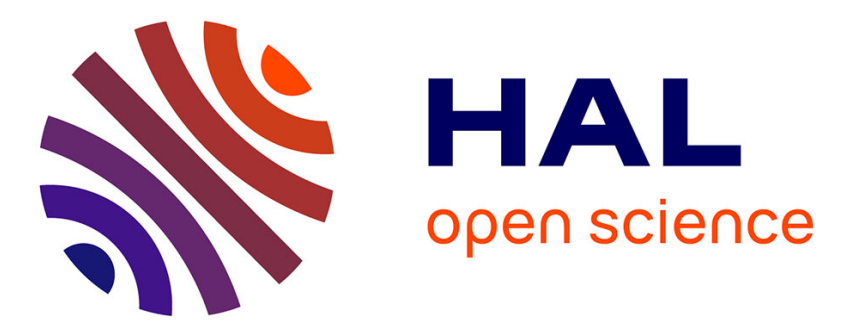

\title{
Exclusion in the field: wild brown skuas find hidden food in the absence of visual information
}

Samara Danel, Jules Chiffard-Carricaburu, Francesco Bonadonna, Anna P Nesterova

\section{- To cite this version:}

Samara Danel, Jules Chiffard-Carricaburu, Francesco Bonadonna, Anna P Nesterova. Exclusion in the field: wild brown skuas find hidden food in the absence of visual information. Animal Cognition, 2021, 24 (4), pp.867-876. 10.1007/s10071-021-01486-4 . hal-03324991

\section{HAL Id: hal-03324991 \\ https://hal.science/hal-03324991}

Submitted on 24 Aug 2021

HAL is a multi-disciplinary open access archive for the deposit and dissemination of scientific research documents, whether they are published or not. The documents may come from teaching and research institutions in France or abroad, or from public or private research centers.
L'archive ouverte pluridisciplinaire HAL, est destinée au dépôt et à la diffusion de documents scientifiques de niveau recherche, publiés ou non, émanant des établissements d'enseignement et de recherche français ou étrangers, des laboratoires publics ou privés. 
1 Exclusion in the field: wild brown skuas find hidden food in the absence of visual information Samara Danel ${ }^{1,2^{*}}$, Jules Chiffard-Carricaburu ${ }^{3 *}$, Francesco Bonadonna ${ }^{3+}$, \& Anna P. Nesterova ${ }^{3,4+}$

$5 \quad{ }^{1}$ Laboratory for the Study of Cognitive Mechanisms, University of Lyon, Bron Rhône-Alpes 6 69500, France.

$7 \quad{ }^{2}$ Max-Planck-Institute for Ornithology, 82319 Seewiesen, Germany.

$8{ }^{3}$ CEFE UMR 5175, CNRS, University of Montpellier, Paul- Valéry Montpellier University 9 EPHE, Montpellier, Cedex 5, France.

$10 \quad{ }^{4}$ PRC, CNRS, INRAE, Université de Tours, UMR 7247, 37380 Nouzilly, France.

$11 *$ These two authors contributed equally to this work and share the first-authorship

12 These two authors contributed equally to this work and share the last-authorship

13 Corresponding authors: correspondence concerning this article should be addressed to

14 Samara Danel: samara.danel@gmail.com

16 16-digit ORCID identifier:

17 Francesco Bonadonna - 0000-0002-2702-5801

18 Jules Chiffard-Carricaburu - 0000-0002-7767-8106

19 Samara Danel - 0000-0003-0233-2343

20 Anna P. Nesterova - 0000-0003-3225-901X

\section{Acknowledgments of support}

23 This work was financed by the French Polar Institute (IPEV): project ETHOTAAF 354 to

24 FB. We are very grateful to Yoanna Marescot for helping with the experiments on the field. 


\section{Abstract}

26 Inferential reasoning by exclusion allows responding adaptively to various environmental

27 stimuli when confronted with inconsistent or partial information. In the experimental context, 28 this mechanism allows selecting correctly between an empty option and a potentially 29 rewarded one. Recently, the increasing reports of this capacity in phylogenetically distant 30 species have led to the assumption that reasoning by exclusion is the result of convergent evolution. Within one largely unstudied avian order, i.e. the Charadriiformes, brown skuas (Catharacta antarctica ssp lonnbergi) are highly flexible and opportunistic predators.

33 Behavioural flexibility, along with specific aspects of skuas' feeding ecology, may act as 34 influencing factors in their ability to show exclusion performance. Our study aims to test 35 whether skuas are able to make choice by exclusion in a visual two-way object-choice task. 36 Twenty-six wild birds were presented with two opaque cups, one covering a food reward. 37 Three conditions were used: 'full information' (showing the content of both cups), 38 'exclusion' (showing the content of the empty cup), and 'control' (not showing any content). 39 Skuas preferentially selected the rewarded cup in the full information and exclusion 40 condition. The use of olfactory cues was excluded by results in the control condition. Our study highlights the cognitive potential of this predatory seabird and opens new investigations for testing further its cognition in the wild.

44 Keywords: avian cognition - Charadriiformes ' cups task · exclusion performance · 45 inferential reasoning 


\section{Introduction}

The capacity of nonhuman animals to choose via exclusion has recently received considerable interest (e.g. Paxton et al. 2018; Nawroth et al. 2014; Petit et al. 2015; Subias et al. 2019). This cognitive mechanism, which refers to 'the ability to understand that if there are only two possibilities and if it is not A, it must be B' (O'Hara et al. 2016), is typically explored through the use of a two-way object-choice paradigm i.e. the cups task (Call 2004; Mikolasch et al. 2012; Pepperberg et al. 2013; Plotnik et al. 2014; Subias et al. 2019). In the visual version of this test, a food reward is hidden underneath one of two identical opaque cups (Darmaillacq et al. 2018). In the crucial phase, the experimenter lifts the empty cup only. The subject is able to choose via exclusion if it excludes the presented empty cup and selects the potentially rewarded, non-lifted one.

Successful performance on this task can be achieved through the use of low- and/or highlevel cognitive strategies (Call 2004; Penn and Povinelli 2007; Watanabe and Huber 2006). Subjects may solve the task by learning to avoid the empty cup, without acquiring any knowledge about the other rewarded container (i.e. low-level strategy). Other individuals, however, may be able of inferring the logical presence of the food under the non-lifted container (i.e. high-level strategy). Although both mechanisms are not mutually exclusive, e.g. one subject can follow a mixed strategy (e.g. Jelbert et al. 2015), choosing by avoiding the incorrect option is less cognitively challenging than inferential reasoning per se (Mikolasch et al. 2012), and may be present in more individuals.

The ability to choose by exclusion has been found in various animals such as elephants (Plotnick et al. 2014), dogs (Aust et al. 2008; Erdőhegyi et al. 2007), goats (Nawroth et al. 2014), or non-human primates (Hill et al. 2011; Sabbatini et al. 2008; Schmitt et al. 2009). In birds, mainly in Corvids and Parrots, some species pass the cups task (e.g. carrion crows Corvus corone, Mikolasch et al. 2012; Clark's nutcracker, Nucifraga Columbiana, Tornick 
and Gibson 2013; red-tailed black cockatoo Calyptorhynchus banksii, Subias et al. 2019), whereas others demonstrate marked difficulties (e.g. Eurasian Jays, Garrulus glandarius, Shaw et al. 2013; jackdaws, Corvus monedula, Schloegl 2011; keas, Nestor notabilis, Schloegl et al. 2009, but see O’Hara et al. 2016).

Whilst some researchers have supported hypotheses about ecological factors promoting the emergence of exclusion in specific animal orders (e.g., 'the adapted intelligence hypothesis' in food-caching corvids e.g. Mikolasch et al. 2012; Schloegl et al. 2009; Schloegl 2011, but see Shaw et al. 2013; 'social complexity' in primates e.g. Petit et al. 2015), others have proposed this ability to be a fundamental cognitive capacity ('general intelligence'; Pepperberg et al. 2013), or, lately, to be of higher importance in flexible foraging species (Nawroth et al. 2014).

A good way to further understand the possible drivers favouring the emergence and evolution of exclusion is to expand the spectrum of species studied with this paradigm in species possessing traits associated with this ability (Marsh et al. 2015; Mikolasch et al. 2011; Schloegl et al. 2009). Moreover, experiments with free-living animal populations are crucial to understand how exclusion performance - and cognitive processes more generally operates under natural conditions (Byrne and Bates 2011; Cauchoix et al. 2017; Völter and Call 2017).

However, as testing individuals in the wild is often prohibitively challenging (Shaw et al. 2015), we still lack studies about the use of exclusion in wild individuals. For instance, species can show high neophobia (preventing their willingness to participate in the task), be non-territorial (struggling with locating individuals when several trials need to be administrated), or live in groups (making difficult their isolation from conspecifics; Shaw et al. 2015). To our knowledge, only two captive exclusion experiments have been conducted 
with wild birds brought into captivity (New Caledonian crows, Corvus moneduloides: Jelbert et al. 2015; Clark's nutcrackers: Tornick and Gibson 2013).

This study aims to assess exclusion performance in a new avian model: the wild brown skua (Catharacta antarctica ssp lonnbergi). This large gull-like seabird frequents Antarctic 103 Peninsula and Subantarctic islands of Atlantic, Indian and Pacific Oceans (Carneiro et al. 104 2014, 2015; Furness et al. 2018). Skuas are top marine predators that display a wide range of 105 feeding techniques i.e. aerial and terrestrial hunting, cannibalism, fishing, kleptoparasitism, and scavenging (Moncorps et al. 1998; Mougeot et al. 1998; Schreiber and Burger 2002). When spatial or seasonal fluctuations in prey availability occur, these birds exhibit high 108 degree of flexibility by adjusting their movements and switching to different resources 109 (Burton 1968; Carneiro et al. 2015). Moreover, skuas can be locally highly selective in their 110 prey intakes and show preferences for hunting specific seabird species (e.g. blue petrel, 111 Halobaena caerulea), while others seem to be avoided (e.g. diving petrels, Pelecanoides 112 urinatrix; Mougeot et al. 1998). Both previous characteristics, behavioural flexibility and 113 selectivity, have been suggested as explanatory factors for exclusion skills in animals 114 (Nawroth et al. 2014). Indeed, some highly flexible species may show higher aversion to 115 losses through the avoidance of the empty container (Nawroth et al. 2014).

116 Regarding one species' feeding ecology may also provide significant insights on the 117 occurrence of exclusion performance under natural conditions (Völter and Call 2017). In the 118 Kerguelen archipelago, some populations (e.g. skuas at Cape Ratmanoff) predate and 119 scavenge mainly on king penguin chicks and eggs (Aptenodytes patagonicus; Furness 1987). 120 In this environment, a penguin egg covered by its incubating parent's fold of skin is often 121 hardly visible (FB, JCC, AN: personal observations). In this context, being able to locate prey 122 without directly perceiving it could be highly adaptive for skuas, which may have favoured 123 the appearance of exclusion performance in the wild (Marsh and Levendoski 2015). 
124 Noteworthy, similarly to other birds endemic to isolated islands (e.g. kea, Nestor notabilis,

125 Gadjon et al. 2006; wild robin, Petroica longipes, Garland et al. 2014), the skua is highly

126 explorative and shows very low neophobia (Furness et al. 2018). It is also highly territorial

127 during the breeding season, forming breeding pairs and establishing a territory that is fiercely

128 defended against conspecific intruders or potential predators (Hahn and Peter 2003;

129 Trivelpiece et al. 1980). Such aspects of this species' feeding ecology, along with complex

130 foraging flexibility and territoriality, make the skua a promising model for exclusion

131 experiments in the field (Gadjon et al. 2006).

132 In this study, we aimed to assess whether wild brown skuas were capable to use exclusion

133 to find hidden food in a visual two-way object choice task. According to the species' feeding

134 ecology, we predict skuas to be able to solve the task.

135 Methods

136 Study population

137 Between Feb 2010 - and Mar 2012, 26 wild brown skuas were tested at Cape Ratmanoff,

138 Courbet Peninsula, Kerguelen Island $\left(48^{\circ} 25-50^{\circ} 00 \mathrm{~S} ; 68^{\circ} 27^{\prime}-70^{\circ} 35 \mathrm{E}\right)$. All birds had a

139 minimum age of 1 year (i.e. colour pattern, uniformity, distinct wing flashes of the body

140 plumage, Furness et al. 2018). Eighteen subjects were individually identified based on leg

141 bands coloured by Darvik@, 2 based on temporary coloured dye sprays (Porcimark@,

142 Langeskov, Denmark, 22 Feb 2010 - 3 Mar 2010), and 6 based on specific aspects of their 143 appearance (i.e. body plumage, presence/absence of scars on the feet' webbing, 2 Mar 2012 -

14410 Mar 2012). In both field seasons, trials were performed between 7 a.m. and 5 p.m. and 145 each subject was tested separately (a second experimenter prevented conspecifics from 146 entering the test area, by approaching and making the intruders leave within approximately 5 147 meters radius of the setup). Prior to the current study, no skua had ever been tested in any 148 exclusion task. 
153 fish flesh to avoid birds to use any smell-related clue. Depending on the procedure (see

154 below), two (training phase) or one container (test phase) held a motivating food reward (a fresh fish piece of Salmo trutta, ca. $3 \mathrm{~g}$ ). At the onset of each trial during all 3 conditions, an opaque blind (a flat wooden board, 30 x $40 \mathrm{~cm}$ ) was placed vertically between the subject and the cups ( $3 \mathrm{~cm}$ before the containers) to prevent subjects from seeing under which cup the experimenter hid the food reward.

160 Procedure

\section{Familiarization phase.}

162 The free-ranging 26 subjects were initially familiarized with the experimental apparatus.

163 When a skua was sufficiently close to the apparatus $(\leq 1$ meter), the experimenter showed 164 two food rewards and placed one under each cup. Skuas were then allowed to touch the cups.

165 Once a subject successfully retrieved the rewards by lifting the cups (4 times within $2 \mathrm{~min}$ ), we considered that it was familiarized with the apparatus.

\section{Test phase.}

168 Three conditions were presented to all birds in the following order: full information, 169 exclusion, and control. In all conditions, the position of the reward was pseudo-randomized 170 and balanced equally on the left/right side in each condition (i.e. Control: left = 93/right = 94;

171 Exclusion: left $=255 /$ right $=263$; Full information: left $=124 /$ right $=126$ ). The subject's

172 choice was considered as correct when the bird lifted the cup and retrieved the reward. The 173 order in which birds participated every day was randomly assigned through the subjects' 
174 voluntary participation. If a bird left the test area during the test and did not return within 1

175 minute, the trial was performed again from the beginning later in the day. During the whole

176 procedure, the experimenter stayed approximately $0.5 \mathrm{~m}$ behind the cups, looking straight

177 ahead.

178 Full information condition. In this condition, we wanted the birds to learn that they would

179 have to make a choice. For that purpose, one reward was hidden under one cup by the 180 experimenter behind the blind. Then, the experimenter removed the blind and both cups were 181 simultaneously lifted so the subject could locate visually which cup contained the food. After $1823 \mathrm{sec}$, both containers were put down in same places and the skua could choose between one 183 of them (see S1 in supplementary material). If the subject lifted the rewarded cup, it was 184 allowed to consume the food. Conversely, if the subject chose the unrewarded cup, the 185 experimenter stopped the trial to prevent the bird from obtaining the food. Each subject received 10 trials in total (60 sec each, max. 10 per day, between $10 \mathrm{sec}-1 \mathrm{~min}$ apart).

Exclusion condition. Same procedure as in Full information condition was followed, except that after baiting, only the empty cup was lifted while the experimenter 189 simultaneously touched the rewarded cup (see S1 in supplementary material). This was made to prevent the reliance on enhancement effects (e.g. the tendency to choose the cup that is manipulated last, Mikolasch et al. 2012; Nawroth et al. 2014). Each subject received 20 trials 192 in total (60 sec each, max. 20 per day, between $10 \mathrm{sec}-1$ min apart).

193 Control condition. We assessed whether the subjects' choices were influenced by the use 194 of olfactory or any other uncontrolled cues. Here, one cup still contained the reward, but 195 subjects had no information about food position i.e. the experimenter did not lift the cups but touched them simultaneously. Each subject received 10 trials in total (60 sec each, max. 10

197 per day, between 10sec-1 min apart).

198 Analysis 
199 All trials were coded live. When the weather allowed (no strong winds, nor flying sand), we 200 also recorded trials using a video camera mounted on a tripod. Inter-observer reliability was 201 not calculated as the subjects' choice in each trial was unambiguous (binary response: 202 success or failure). We modelled birds' success probability at trials as a random variable 203 following a binomial distribution. To compare birds' performance depending on test 204 condition and to assess the possible effects of lateralization and learning, the probability to 205 find the reward was modelled as a function of test condition (full information, exclusion, control), position of the food (right/left), and trial number (or ID_trial), in a generalized linear mixed-effects model (GLMM). To account for individual differences in probability to pass 208 the test, we set individual identity as a random effect with a Gaussian distribution in the error 209 structure of the model. We implemented generalized linear mixed-effects model trees 210 (Fokkema et al. 2019) to identify relevant clusters and effects. The algorithm finds subgroups 211 (or terminal nodes) that differ in their success rate, while taking into account the nested 212 structure of the dataset (individuals). The algorithm evaluates the stability of model 213 parameters (i.e. stability of the intercept coefficient) at each node. The node becomes 214 terminal (stable) if $\mathrm{p}>0.05$ for all splitting variable of the model.

215 As position of the food (right or left cup) was not available for all testing sequences, we implemented two trees. Model tree I was based on a reduced dataset with only individuals for 217 whom we had full information on the position of food (left/right) within the 3 conditions $(n=$ 218 19). This first model was implemented with test condition and food position effects in 219 interaction. Model tree II was implemented on the complete dataset including all the 220 individuals $(\mathrm{N}=26)$. We back transformed coefficients from the logit scale to get success 221 probabilities on the response scale. We refer to these transformed coefficients as probability 222 of success (Ps). Ps is reported with 95\% confidence intervals. All the analyses were carried 
223 out with R version 3.6 (R Core Team, 2019), and glmertree package (Fokkema et al. 2019)

224 was used to perform the analysis.

\section{Results}

226 Model tree I: test conditions and food position

227 With the model accounting for food position, we identified a difference in success probability 228 between each of the 3 experimental conditions (control, exclusion and full information), as well as an effect of food position on success during control tests. Results are shown in Fig. 2.

231 There was a difference in performance between the control condition and the exclusion/full

232 information condition ( $p<0.001$; Node 1). Food position had an effect on success probability 233 but only within the control condition ( $p=0.023$; Node 2$)$ : birds' success probability was Ps $=$ 2340.43 [95\% IC: $0.32-0.54]$ when food was on the left (Node 3), and Ps $=0.62$ [95\% IC: 0.47 $235-0.75]$ when the reward was located on the right (Node 4). Thus, there was a mean side bias 236 towards the right container during this condition. At the individual scale, we could detect 237 birds $100 \%$ lateralized (Left side: $\mathrm{N}=1$, right side: $\mathrm{N}=3$ ). Skuas were on average more 238 successful in the full information condition (Ps $=0.74$ [95\% IC: $0.63-0.83]$ ) than in the exclusion condition $(\mathrm{Ps}=0.64$ [95\% IC: $0.53-0.74])(p=0.024$; Node 5).

Model tree II: test conditions and learning

241 With the model accounting for trial number (complete dataset), we identified a difference

242 between each of the 3 experimental conditions (control, exclusion and full information), as 243 well as an effect of trial number (ID_trial) during exclusion tests. Results are shown in Fig. 3. < Fig. 3 about here >

245 There was a difference in performance between the control condition and the exclusion/full 246 information condition ( $p<0.001$; Node 1). Mean success probability during the control 247 condition (Node 2) was Ps $=0.51$ [95\% IC: $0.43-0.59$ ]. The model tree procedure identified 
248 a difference between the exclusion and full information condition $(p=0.021$; Node 3$)$.

249 During the exclusion condition, there was a difference between the first 12 trials and the last

2508 trials $(p=0.021$; Node 4$)$, with an average success probability Ps $=0.58$ [95\% IC: $0.49-$

251 0.67] during the first 12 trials (Node 5), and an average success probability Ps $=0.71[95 \%$

252 IC: $0.62-0.79$ ] during the last 8 trials (Node 6). Thus, there was a learning effect emerging

253 over the course of the exclusion condition. During the full information condition (Node 7),

254 mean success probability was Ps $=0.72$ [95\% IC: $0.64-0.80]$.

\section{Discussion}

256 Overall, our results demonstrate that free-living skuas are capable of showing exclusion

257 performance. Subjects succeeded above the level expected by chance in the full information

258 and exclusion conditions, and their performances confirm that they did not use olfactory cues

259 (smell of the hidden food reward) in the control condition. This experiment is the first to

260 reveal exclusion skills in Charadriiformes within a natural setting.

261 When no information was available (control condition), most birds failed in locating the

262 baited cup above chance. This result is not surprising when we refer to the species' biological

263 and behavioural features. Skuas possess small olfactory bulbs and display no reaction when

264 faced to striking odour changes of a same food item (Furness et al. 2018). Noteworthy, a

265 mean side bias emerged over trials in the control condition with a mean preference to select

266 the right cup in tested individuals. At the individual level, four subjects chose constantly the

267 same side (three skuas selected the right one, one the left one). This behaviour is not

268 uncommon when subjects are confronted with two-way object-choice tasks (e.g. Danel et al.

269 2018; Gagne et al. 2012; Ketchaisri et al. 2019), and represents a useful strategy when

270 environmental stimuli are unpredictable, such as in our control condition (Jacobs and Osvath

271 2015; Ketchaisri et al. 2019; Plotnik et al. 2013; Tebbich et al. 2007). In contrast, skuas were

272 able to derive relevant information from the full information and exclusion conditions 
273 without displaying any side bias, probably because both conditions were predictable.

274 Similarly to other avian species (e.g., African grey parrots, Mikolasch et al. 2011, 275 Pepperberg et al. 2013, Schloegl et al. 2012; carrion crows, Mikolasch et al. 2012; Clark’s 276 nutcrackers, Tornick and Gibson 2013; Eurasian jays, Shaw et al. 2013; jackdaws, Schloegl 277 et al. 2011; keas, Schloegl et al. 2009; ravens, Schloegl et al. 2009; red-tailed black 278 cockatoos, Subias et al. 2019), skuas chose significantly more the rewarded cup over the 279 unrewarded one in the full information condition (success probability Ps $=0.72[95 \%$ IC: $0.64-0.80])$. Our results indicate that this species was able to rely on direct visual information for solving the task. We also suggest that skuas showed spontaneous object 282 permanence (Piaget 1954), i.e. the understanding that hidden objects do not cease to exist 283 (Pepperberg et al. 2013), as they successfully selected the opaque container covering the food 284 reward.

Crucially, this species was also able to use indirect information (i.e. the view of the empty cup) to choose substantially more the baited cup over the unbaited one in the critical exclusion condition (success probability Ps $=0.64$ [95\% IC: $0.53-0.74]$ ). Unlike other captive avian species (e.g., Schloegl et al. 2009), skuas in this experiment did not require extensive training and all birds were naive to experimental testing. In this case, the subjects may not have had the time to learn the causal cues (low-level explanation i.e. avoidance of the empty cup) required to solve the task (Nawroth et al. 2014; Shaw et al. 2013; Schloegl 2011; Schloegl et al. 2009). Moreover, exclusion performance might not normally require elementary associative learning when a limited number of tests is proposed (Darmaillacq et al. 2018; Shaw et al. 2013). However, we found a progressive amelioration in subjects' performance over trials within the exclusion condition. We therefore cannot rule out the possibility that subjects have used a non-costly cognitive strategy through the avoidance of 297 the empty cup in the following trials (Call 2006; Paukner et al. 2009; Mikolasch et al. 2012; 
298 Schmitt and Fischer 2009). Only a further study with proper controls will clarify the use of 299 low-level strategies in this species (e.g. see the different tests used in Call 2006 and in 300 Mikolasch et al. 2011, with the procedure pioneered by Premack and Premack 1994; or the 301 follow-up conditions of the modified tubes task employed by Jelbert et al. 2015). Future 302 experiments may also assess whether wild skuas still show success when they are confronted 303 with an increased number of containers, such as in the 3-cups object choice task (Grether and 304 Maslow 1937). This version may provide contrasting results and is considered more complex than the binary cups task (Marsh et al. 2015).

At first glance, our results support the adaptive specialisation hypothesis (De Kort and 307 Clayton 2006), which suggests that cognitive abilities may vary depending on specific 308 aspects of one species' feeding ecology. Referring to this assumption, Nawroth et al. (2014) recently found a link between highly selective feeding behaviour and exclusion performance in small ruminants. Although it would be tempting to propose similar mechanisms operating 311 in our model species, only a comparative approach may reveal the potential role behavioural 312 flexibility plays in exclusion. For instance, further experiments may test exclusion 313 performance in skuas' genetically related species that possess different feeding ecologies, e.g. specialist predators such as long-tailed skuas (Stercorarius longicaudus, Sitter et al. 2011).

316 by their preys (Grant and Samways 2015; Rice 1982; Schmitt and Fischer 2009). Although 317 vision seems to play a significant role in skuas' ecology, this species relies also on acoustic 318 information during foraging (Furness 1987). For instance, on Mayès Island, Kerguelen 319 archipelago, acoustic information helps specialized skuas in finding burrow-nesting birds at 320 night (Mougeot and Bretagnolle 2000). Thus, in order to determine potential variations in 321 levels of exclusion performance across sensory modalities, further experiments should assess 322 skuas' capacity to locate hidden food when given acoustic information. 
In conclusion, wild brown skuas are capable of showing exclusion performance in the visual domain. Although the role ecological traits play in the emergence of exclusion performance must be the object of further research, our results corroborate the hypothesis that this capacity has emerged in distantly related taxa through convergent evolution (O'Hara et al. 2015). Skuas possess life history and ecological traits that are commonly linked to enhanced cognition (Morand-Ferron et al. 2007; Ricklefs 2004) e.g. late sexual and physical maturity, longevity, high innovation rate, kelptoparasitism, and generalism (Chester 1993; Furness et al. 2020; Spear et al. 1999). However, to date, we are aware of only one previous experimental cognitive work showing the capacity of skuas to recognize human faces (Lee et al. 2016). Research is needed to explore further the cognitive abilities of this promising new model system. We also hope this study will encourage future field comparative work on this capacity across taxonomic groups, so as to enhance our current view of the distribution of exclusion skills in avian phylogeny.

\section{References}

Allaire J, Xie Y, McPherson J, Luraschi J, Ushey K, Atkins A, Wickham H, Cheng J, Chang W, Iannone R (2020). rmarkdown: Dynamic Documents for $R$. R package version 2.3, https://github.com/rstudio/rmarkdown.

Aust U, Range F, Steurer M, Huber L (2008) Inferential reasoning by exclusion in pigeons, dogs, and humans. Anim cogn 11:587-597.

342 Burton RW (1968) Breeding biology of the brown skua, Catharacta skua lonnbergi (Mathews), at Signy Island, South Orkney Islands. Brit Antarct Surv B 15:9-28.

344 Byrne RW and Bates LA (2011) Cognition in the wild: exploring animal minds with observational evidence. Biol Lett 7:619-622.

346 Call J (2004) Inferences about the location of food in the great apes (Pan paniscus, Pan troglodytes, Gorilla gorilla, and Pongo pygmaeus). J Comp Psychol 118:232-241. 
348 Call J (2006) Inferences by exclusion in the great apes: the effect of age and species. Anim Cogn 9:393-403.

350 Carneiro APB, Manica A, Phillips RA (2014) Foraging behaviour and habitat use by brown skuas Stercorarius lonnbergi breeding at South Georgia. Mar Biol 161:1755-1764.

352 Carneiro AP, Manica A, Trivelpiece WZ, Phillips RA (2015) Flexibility in foraging strategies of Brown Skuas in response to local and seasonal dietary constraints. J Ornithol 156:625-633.

Cauchoix, M., Hermer, E., Chaine, A. S., \& Morand-Ferron, J. (2017). Cognition in the field: comparison of reversal learning performance in captive and wild passerines. Sci Rep 7:1-10.

358 Chester SR (1993) Antarctic birds and seals. Wandering Albatross, San Mateo.

359 Danel S, von Bayern AM, Osiurak F (2019) Ground-hornbills (Bucorvus) show means-end understanding in a horizontal two-string discrimination task. J Ethol 37:117-122.

361 Darmaillacq AS, Dickel L, Avargues-Weber A, Duboscq J, Dufour V, Jozet-Alves C 2018 Cognition animale: perception, raisonnement et représentations. Dunod.

363 De Kort SR and Clayton NS (2006) An evolutionary perspective on caching by corvids. Proc R Soc B 273:417-423.

365 Erdőhegyi Á, Topál J, Virányi Z, Miklósi Á (2007) Dog-logic: inferential reasoning in a twoway choice task and its restricted use. Anim Behav 74:725-737.

367 Fokkema M, Smits N, Zeileis A, Hothorn T, Kelderman H (2018) Detecting TreatmentSubgroup Interactions in clustered Data With Generalized Linear Mixed-Effects Model Tree Behav Res Methods 50:2016-2034.

370 Furness RW (1987) The Skuas. Carlton, Pyser Press. 
371 Furness RW, Boesman P, Garcia EFJ (2018) The Brown Skua (Catharacta antarctica). In: del Hoyo J, Elliott A, Sargatal J, Christie DA, de Juana E (eds) Handbook of the Birds of the World Alive. Lynx Edicions, Barcelona.

374 Gagne M, Levesque K, Nutile L, Locurto C (2012) Performance on patterned string problems by common marmosets (Callithrix jacchus). Anim Cogn 15:1021-1030.

Gajdon GK, Fijn N, Huber L (2004) Testing social learning in a wild mountain parrot, the kea (Nestor notabilis). Anim Learn Behav 32:62-71.

Garland A, Low J, Armstrong N, Burns KC (2014) Wild robins (Petroica longipes) respond to human gaze. Anim Cogn 17:1149-1156.

Grant PB and Samways MJ (2015) Acoustic prey and a listening predator: interaction between calling katydids and the bat-eared fox. Bioacoustics 24:49-61.

Grether WF and Maslow AH (1937) An experimental study of insight in monkeys. J Comp Psychol 24:127-134.

Hahn S, Peter, HU (2003) Feeding territoriality and the reproductive consequences in brown skuas Catharacta antarctica lonnbergi. Polar Biol 26:552-559.

Hill A, Collier-Baker E, Suddendorf T (2011). Inferential reasoning by exclusion in great apes, lesser apes, and spider monkeys. J Comp Psychol 125:91-103.

Jelbert SA, Taylor AH, Gray RD (2015) Reasoning by exclusion in New Caledonian crows (Corvus moneduloides) cannot be explained by avoidance of empty containers. J Comp Psychol 129:283-290.

Ketchaisri O, Siripunkaw C, Plotnik JM (2019) The use of a human's location and social cues by Asian elephants in an object-choice task. Anim Cogn 22:907-915. individual humans. Anim Cogn 19:861-865. 
395 Marsh HL, Vining AQ, Levendoski EK, Judge PG (2015) Inference by Exclusion in LionTailed Macaques (Macaca silenus), a Hamadryas Baboon (Papio hamadryas), Capuchins (Sapajus apella), and Squirrel Monkeys (Saimiri sciureus). J Comp Psychol, $3: 256-267$.

Mikolasch S, Kotrschal K, Schloegl C (2011) African grey parrots (Psittacus erithacus) use inference by exclusion to find hidden food. Biol Lett 7:875-877.

Mikolasch S, Kotrschal K, Schloegl C (2012) Is caching the key to exclusion in corvids? The case of carrion crows (Corvus corone corone). Anim Cogn 15:73-82.

Moncorps S, Chapuis J, Haubreux D, Bretagnolle V (1998) Diet of the Brown Skua Catharacta skua lonnbergi on the Kerguelen archipelago: comparisons between techniques and between islands. Polar Biol 19:9-16.

Morand-Ferron J, Sol D, Lefebvre L (2007) Food stealing in birds: brain or brawn? Anim Behav 74:1725-1734.

Mougeot F, Bretagnolle V (2000) Predation as a cost of sexual communication in nocturnal seabirds: an experimental approach using acoustic signals. Anim Behav 60: 647-656.

410 Mougeot F, Genevois F, Bretagnolle V (1998) Predation on burrowing petrels by the brown skua (Catharacta skua lonnbergi) at Mayes Island, Kerguelen. J Zool 244:429-438.

412 Nawroth C, von Borell E, Langbein J (2014) Exclusion performance in dwarf goats (Capra aegagrus hircus) and sheep (Ovis orientalis aries). PLoS One 9:e93534.

414 O’Hara M, Auersperg AM, Bugnyar T, Huber L (2015) Inference by exclusion in Goffin cockatoos (Cacatua goffini). PLoS One 10:e0134894.

416 O’Hara M, Schwing R, Federspiel I, Gajdon GK, Huber L (2016) Reasoning by exclusion in the kea (Nestor notabilis). Anim Cogn 19, 965-975. 
418 Paukner A, Huntsberry ME, Suomi SJ (2009) Tufted capuchin monkeys (Cebus apella) spontaneously use visual but not acoustic information to find hidden food items. $\mathrm{J}$ Comp Psychol 123:26-33.

Paxton Gazes R, Chee NW, Hampton, RR (2018) Monkeys choose, but do not learn, through exclusion. Anim Behav Cogn 5:1-25.

423 Penn DC, Povinelli, DJ (2007) Causal cognition in human and nonhuman animals: a 424 comparative, critical review. Annu Rev Psychol 58:97-118.

425 Pepperberg IM, Koepke A, Livingston P, Girard M, Hartsfield LA (2013) Reasoning by inference: Further studies on exclusion in grey parrots (Psittacus erithacus). J Comp Psychol 127:272-281.

Petit O, Dufour V, Herrenschmidt M, De Marco A, Sterck EH, Call J (2015). Inferences about food location in three cercopithecine species: an insight into the socioecological cognition of primates. Anim Cogn 4:821-830.

Piaget J (1954) The construction of reality in the child. New York, NY: Basic Books.

Plotnik JM, Pokorny JJ, Keratimanochaya T, Webb C et al (2013) Visual cues given by humans are not sufficient for Asian elephants (Elephas maximus) to nd hidden food. PLoS One 8:e61174.

Plotnik JM, Shaw RC, Brubaker DL, Tiller LN, Clayton, SC (2014) Thinking with their trunks: elephants use smell but not sound to locate food and exclude nonrewarding alternatives. Anim Behav 88:91-98.

Premack D, Premack AJ (1994) Levels of causal understanding in chimpanzees and children. Cognition 50:347-362.

R Core Team (2019) R: A language and environment for statistical computing. R Foundation for Statistical Computing, Vienna, Austria. URL https://www.R-project.org/.

442 Rice WR (1982) Acoustic location of prey by the marsh hawk: adaptation to concealed prey. The Auk 19:403-413. 
444 Ricklefs RE (2004) The cognitive face of avian life histories: the 2003 Margaret Morse Nice lecture. Wilson J Ornithol 116:119-133.

Sabbatini G and Visalberghi E (2008) Inferences about the location of food in capuchin monkeys (Cebus apella) in two sensory modalities. J Comp Psychol 122:156-166.

Schloegl C (2011) What you see is what you get-reloaded: can jackdaws (Corvus monedula) find hidden food through exclusion? J Comp Psychol 125:162-174.

Schloegl C, Dierks A, Gajdon GK, Huber L, Kotrschal K, Bugnyar T (2009) What you see is what you get? Exclusion performances in ravens and keas. PloS One 4:e6368.

Schloegl C, Schmidt J, Boeckle M, Weiß BM, Kotrschal, K (2012) Grey parrots use inferential reasoning based on acoustic cues alone. Proc R Soc B 279:4135-4142.

Schmitt V and Fischer J (2009) Inferential reasoning and modality dependent discrimination 455 learning in olive baboons (Papio hamadryas anubis). J Comp Psychol 123:316-325.

Schreiber EA, Burger J 2002 Biology of marine birds. CRC Press, Boca Raton, FL.

Shaw RC, Boogert NJ, Clayton NS, Burns KC (2015) Wild psychometrics: evidence for 'general' cognitive performance in wild New Zealand robins, Petroica longipes. Anim Behav 109:101-111.

Shaw RC, Plotnik JM, Clayton NS (2013) Exclusion in corvids: The performance of foodcaching Eurasian jays (Garrulus glandarius). J Comp Psychol 127:428-435.

Sittler B, Aebischer A, Gilg O (2011) Post-breeding migration of four Long-tailed Skuas (Stercorarius longicaudus) from North and East Greenland to West Africa. J Ornithol 152: 375-381.

Spear LB, Howell SNG, Oedekoven CS, Legay D, Bried J (1999) Kleptoparasitism by brown skuas on albatrosses and giant-petrels in the Indian ocean. Auk 116:545-548.

467 Subias L, Griffin AS, Guez, D (2019) Inference by exclusion in the Red- tailed Black 468 Cockatoo (Calyptorhynchus banksii). Integr Zool 14:193-203. 
469 Tebbich S, Seed AM, Emery NJ, Clayton NS (2007) Non-tool-using rooks, Corvus $470 \quad$ frugilegus, solve the trap-tube problem. Anim Cogn 10:225-231.

471 Tornick JK and Gibson BM (2013) Tests of inferential reasoning by exclusion in Clark's 472 nutcrackers (Nucifraga columbiana). Anim Cogn 16:583-597.

473 Trivelpiece W, Butler RG, Volkman NJ (1980) Feeding territories of Brown Skuas $474 \quad$ (Catharacta lonnbergi). Auk 97:669-676.

475 Völter CJ and Call J (2017) Causal and inferential reasoning in animals. In J Call, GM 476 Burghardt, IM Pepperberg, CT Snowdon, \& $\mathrm{T}$ Zentall (Eds.), APA handbooks in 477 psychology®. APA handbook of comparative psychology: Perception, learning, and 478 cognition (p. 643-671). American Psychological Association.

479 Watanabe S and Huber L (2006) Animal logics: decisions in the absence of human 480 language. Anim Cogn 9:235-245. 
481 Figure captions

482 Fig. 1 Schematic representation of the conditions and the experimental setup for a typical exclusion test trial. (a) The 'full information', 'exclusion', and 'control' conditions are

484 presented from left to right, respectively (b) Two identical opaque cups are simultaneously 485 showed on a wooden platform. In the sketch, the reward is located under the right cup. The 486 subject is watching a human experimenter lifting the empty left cup. To solve the task, the 487 skua must exclude the left cup (low-level explanation) and/or infer that the right cup covers 488 the reward (high-level explanation), by raising this container accordingly.

489 Fig. 2 Model tree I: test conditions and food position. The Tree shows skuas' estimated mean 490 success probabilities in each of the terminal nodes during the different test conditions, 491 including the potential effect of food position during the control condition. The black bars 492 show 95\% confidence intervals associated with estimated means. Dots show the observed 493 performance of each individual during the different tests between 0 and 1 (0 to 100\% 494 success), dots' colour include transparency so that darker dots show that multiple individuals 495 performed with the same success rate.

496 Fig. 3 Model tree II: test conditions and learning. The Tree shows skuas' estimated mean 497 success probabilities in each of the terminal nodes during the different test conditions, 498 including the potential effect of learning through trial number (ID_trial) during the exclusion 499 condition. The black bars show the 95\% confidence intervals associated with estimated 500 means. Dots show the observed performance of each individual during the different tests 501 between 0 and 1 ( 0 to $100 \%$ success), dots' colour include transparency so that darker dots 502 show that multiple individuals performed with the same success rate. 


\section{Electronic supplementary material}

504 S1. Video of test trial examples in the full information and the exclusion conditions, 505 respectively. 
a

Experimental conditions

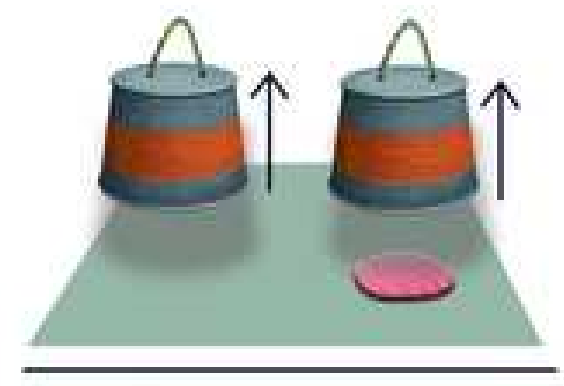

Full information
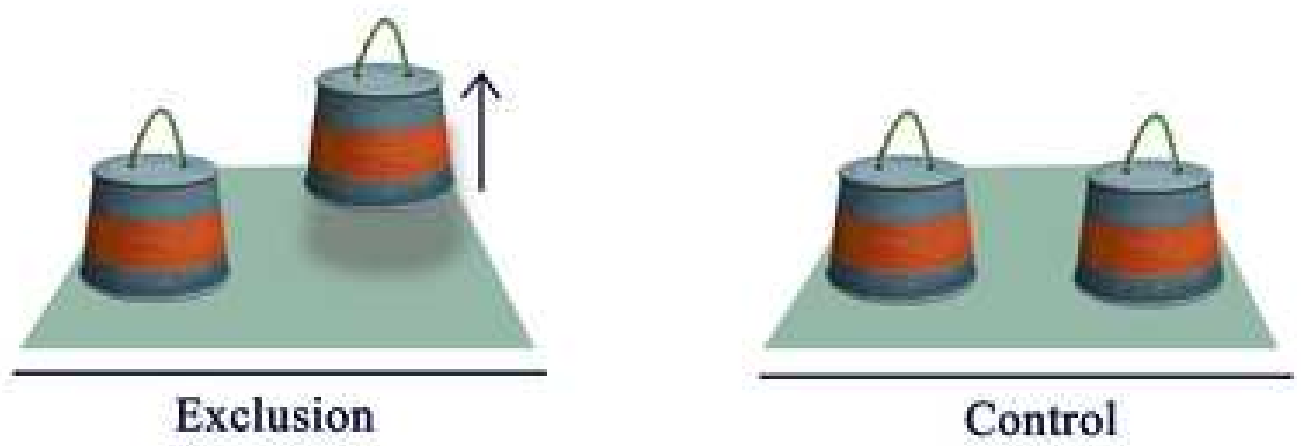

Control

b

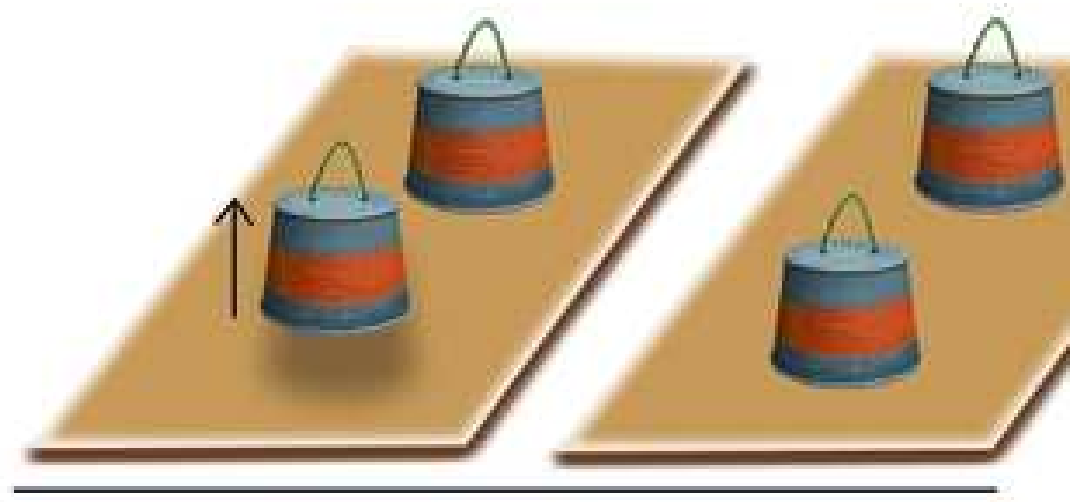

Presentation stage

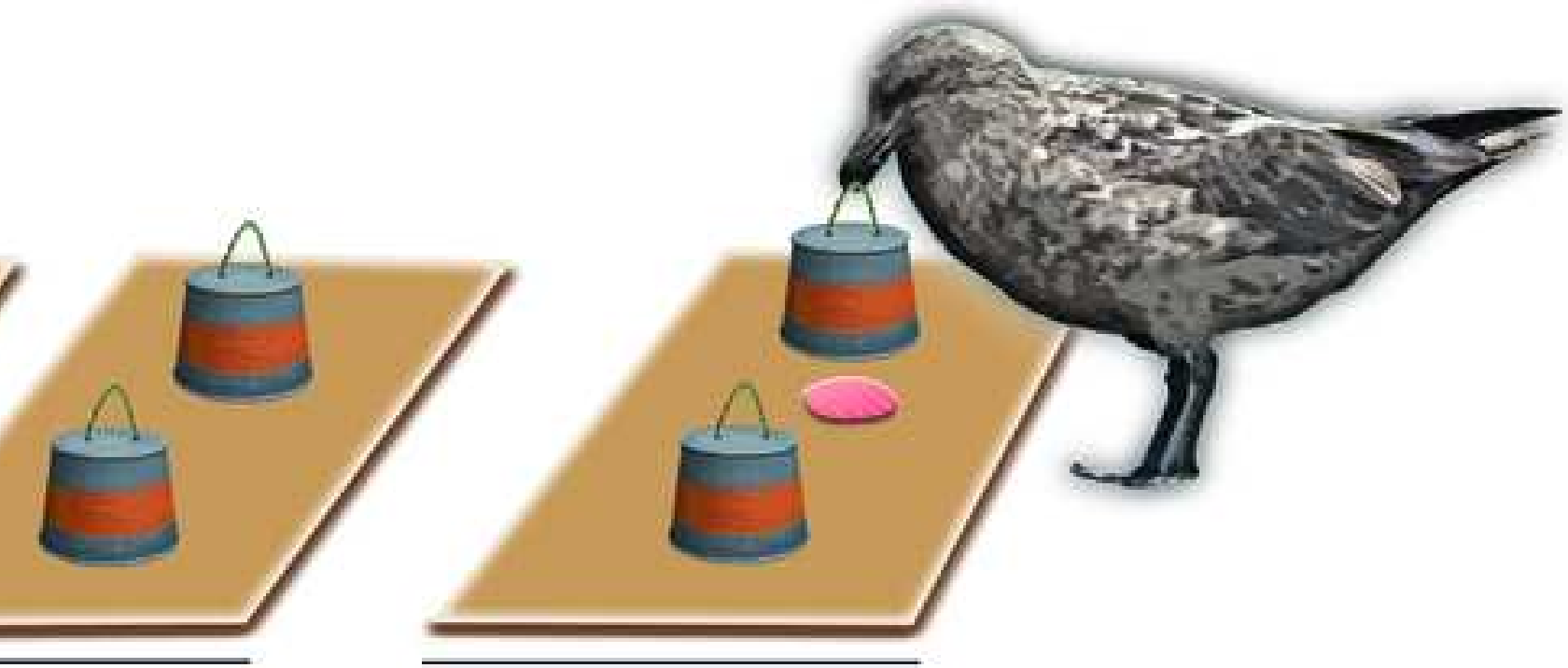

Choice stage

Exclusion: test trial 
Fig. 2

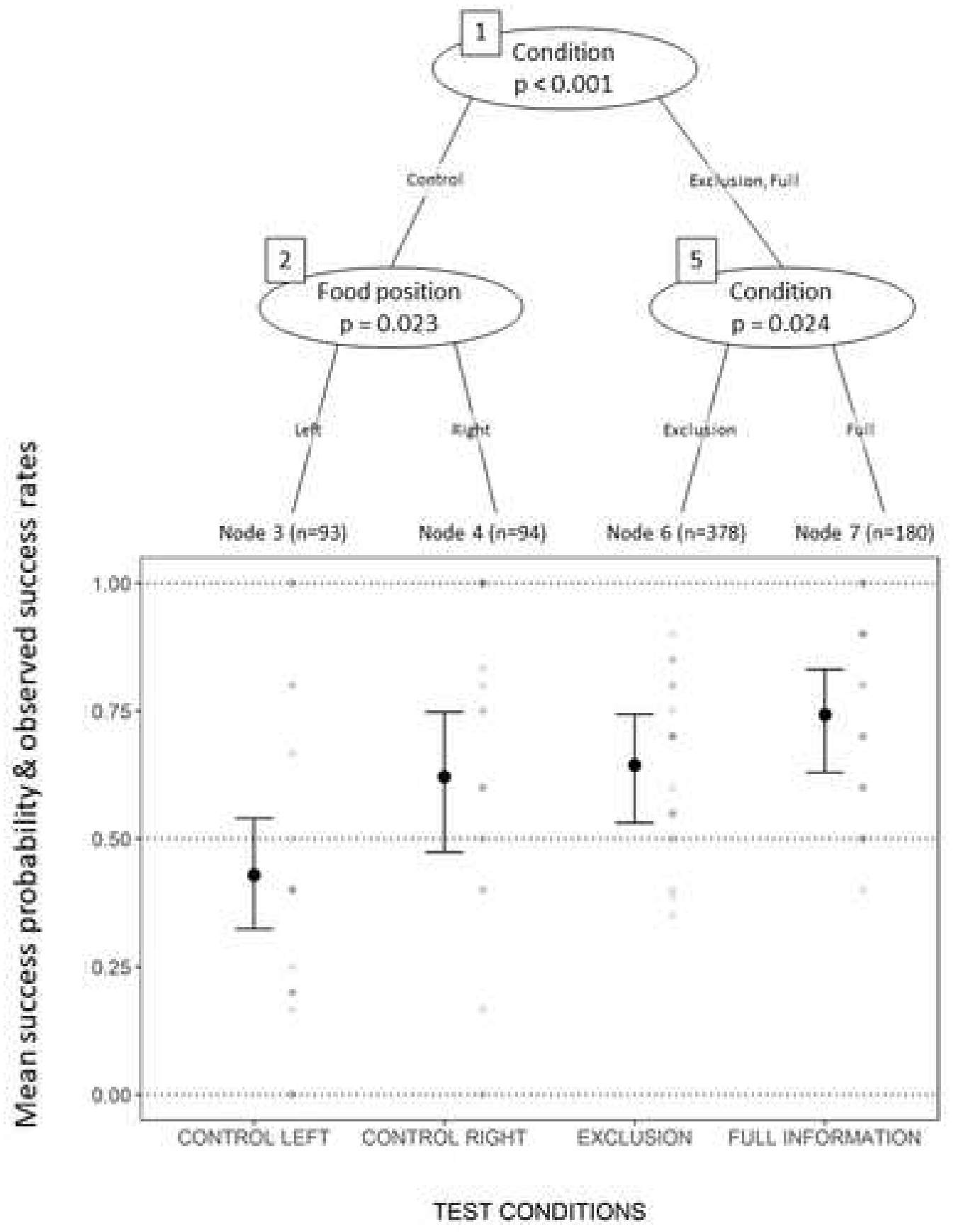


Fig. 3

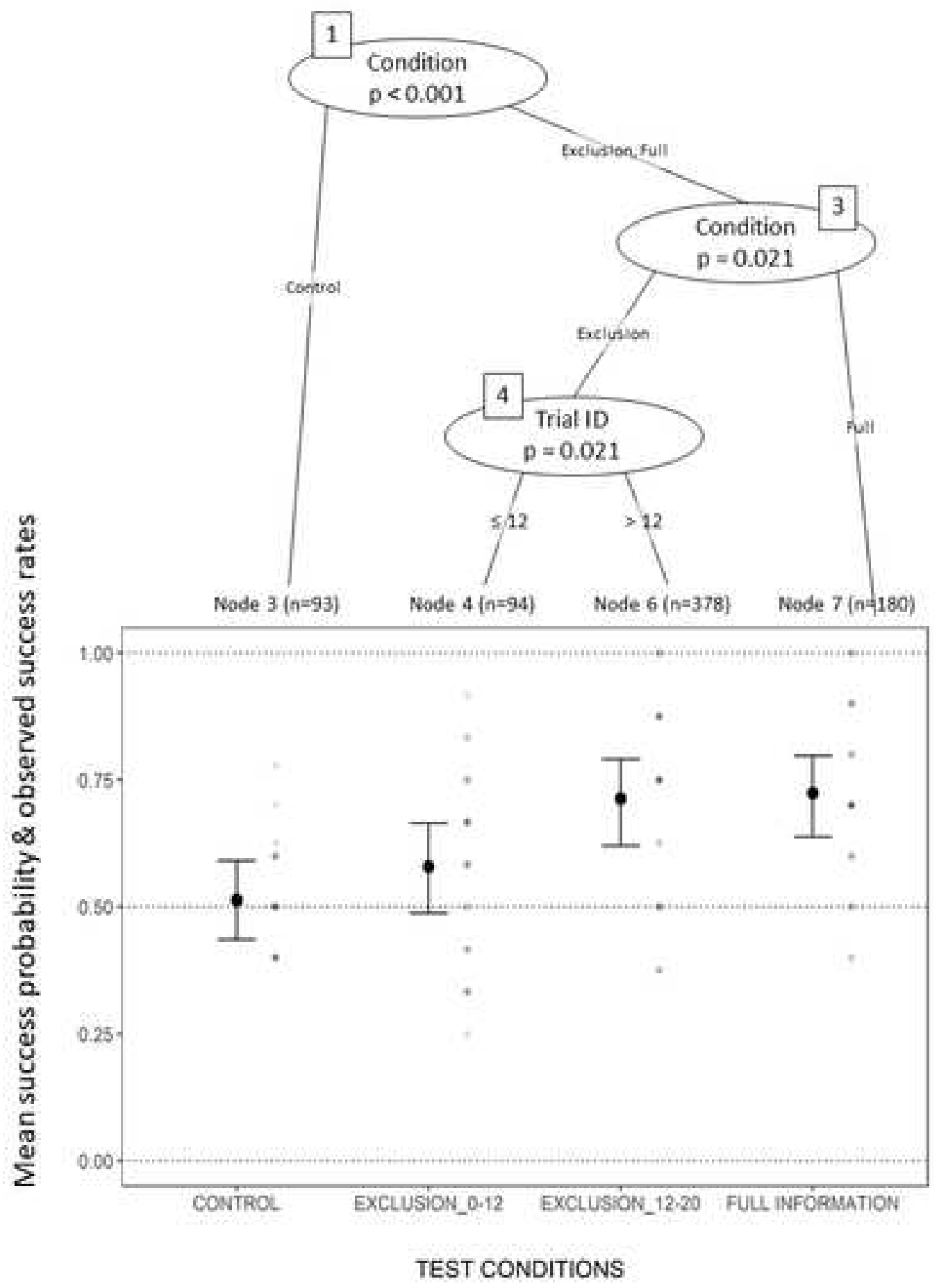

